\title{
Engineering Frameworks for a High School Setting: Guidelines for Technical Literacy for High School Students
}

\author{
Catherine Koehler ${ }^{1}$, Elias Faraclas ${ }^{2}$, Sonia Sanchez ${ }^{2}$, S. Khalid Latif ${ }^{2}$, \\ Kazem Kazerounian ${ }^{2}$ \\ ${ }^{1}$ Neag School of Education/ \\ ${ }^{2}$ School of Engineering \\ University of Connecticut \\ Storrs, CT 06268
}

\begin{abstract}
$\underline{\text { Abstract }}$
The introduction of engineering concepts into the classroom is a relatively new idea that is being adopted and written into several state science frameworks. As part of a National Science Foundation grant titled, da Vinci Ambassadors in the Classroom - The Galileo Project, graduate fellows in the Project have developed a set of engineering education frameworks (EEF) that describe what technically literate students should know by the time they graduate from high school. These novel engineering frameworks incorporate concepts in the fields of mathematics, science and engineering with a systematic approach to a prescribed high school curriculum that promotes technical literacy. Currently, the educational structure in the disciplines of mathematics and science, have content frameworks that describe what students should know by the time they graduate from high school. The organizations that govern discipline standards, the National Research Council (for science) and the National Council of Teachers of Mathematics, have defined content standards and how to implement these standards into the classroom. These math and science standards outline the pathway that guide student's content knowledge in mathematics and science from kindergarten through $12^{\text {th }}$ grade. However, it has been suggested that engineering concepts be incorporated into the traditional math and science frameworks and be implemented into the high school curriculum, resulting in a paradigm shift from rigid, content driven, discipline-specific course work to a more problem based engineering decision making model. The challenge for school districts to incorporate the engineering frameworks into the current science and mathematics curriculum thereby promoting technical literacy for their high school students, will be necessary in order for students to fully understand increasingly complex technology they will face in their everyday lives.
\end{abstract}

\section{Introduction}

The fundamental focus currently facing education curriculum developers in all disciplines is ensuring that students have a broad and relevant knowledge base by the time they graduate from high school. However, the current Federal Administration, with its new education reform 
plan, No Child Left Behind (NCLB), claims that American students are falling behind their international counterparts in science and mathematics. As such, new high stakes testing initiatives to "prove" that students are "learning" are being implemented at an alarming rate. It is essential that students from the United States are competent in mathematics and science however, in today's global economy it is increasingly important that our students are also competitively competent with technology. Results from research conducted in the 1989 study titled, Pupils' Attitude Toward Technology, (PATT) ${ }^{[1]}$ indicated that most students who participated were unaware of the history and evolution of technology as well as the functionality of modern technological systems. With the current emphasis on science and mathematics, coupled with the lack of appropriate frameworks to promote technical literacy, it is questionable that the current generation of students will be adequately prepared and competitive for the modern technologically-driven global market.

As a result of NCLB, the legislation mandates students to demonstrate proficiency in mathematics and science with little to no focus on the technology. Science education has evolved and has been driven by reform efforts ever since the launching of the satellite, Sputnik, in 1957. Much of the focus on science education has revolved around the development of "scientific literacy." The phrase, 'scientific literacy' was first introduced nearly a half-century ago, yet unfortunately, not everyone agrees to what scientific literacy is ${ }^{[2]}$. Although claimed to be the principle outcome of science education, the concept does not underpin the majority of science teaching and learning across the nation today. Some claim that it is just a slogan to rally educators to promote better science education programs ${ }^{[3]}$ while others argue that scientific literacy is an ideal that can never be achieved in public education ${ }^{[4]}$. A "science-literate person," according to the American Association for the Advancement of Science (AAAS) publication, Science for All Americans: Project $2061^{[5]}$, is

"one who is aware that science, mathematics and technology are interdependent human enterprises with strengths and limitations; understands key concepts and principles of science; is familiar with the natural world and recognizes both its diversity and unity; and uses scientific knowledge and scientific ways of thinking for individual and social purposes."

In attempts to provide a fundamental foundation to what should be taught in public school science programs, organizations such as American Association for the Advancement of Science (AAAS) and National Research Council (NRC) took the initiative to embark on the new wave of science educational reform. Their efforts began by defining scientific literacy and the necessary pathway to take to achieve it. These efforts began to shape the "new" science curriculum in American public high schools. Publications directing these efforts included the AAAS' documents, Science for All Americans ${ }^{[5]}$ and Benchmarks for Scientific Literacy ${ }^{[6]}$, the National Science Teachers Association (NSTA) publication, Scope, Sequence and Coordination of Secondary School Science [7], and the NRC publication, National Science Education Standards ${ }^{[8]}$. Each document had the goal to describe and define what should be taught in the science classroom. These documents served as policy statements and have paved the way for long-term improvements in science education.

"Proceedings of the 2005 American Society for Engineering Education Annual Conference \& Exposition Copyright $($ C 2005, American Society for Engineering Education” 
Most educators would argue that the traditional high school curriculum is already "packed" with content and do not believe that there is room left in the school day for the average student to include technology and engineering into their repertoire. However, it may be argued that there is substantial room in the curriculum for technology and engineering through proper integration with traditional content. Unfortunately, the focus of mathematics and science education in the public schools has neglected to include adequate technology content or to promote a general state on technical literacy. Recommendations from the AAAS ${ }^{[5,6]}$ and NRC [8] documents do address technology as a subset of the content standards but these recommendations have not proven enough fuel to ignite the fire for technical literacy at least in the current curriculum climate. The training of teachers through professional development and the development of guidelines to facilitate the teaching of technical literacy is equally as important if an educational objective is to produce a technically literate society who can be competitive in the future global market.

In an attempt to foster technical literacy in grades K12, the International Technology Education Association (ITEA) has developed technology education standards as a means to identify a content of study for technology. ${ }^{[9]}$ Although ITEA standards are available to state curriculum committees as guidelines for technical literacy, some states have chosen to develop their own engineering/technology curriculum standards. Massachusetts is currently the one of the only states that has written engineering standards into their curriculum frameworks. These curriculum guidelines are titled, 'Science and Technology/Engineering Frameworks' and are being implemented throughout Massachusetts classrooms today. Other states have less defined engineering education standards but they have components of engineering written into their state curriculum guidelines. Technology education curriculum frameworks in Connecticut contain two standards which support engineering education: Technological Impacts and Engineering Design. The content standard, Technological Impacts, states that "students will understand the impact that technology has on the social, cultural and environmental aspects of their lives", which aligns with the concept of technical literacy, although minimally. Additionally, stated in these frameworks, is the engineering design process however implementation of the process is lacking in the guidelines. An attempt was made to include engineering concepts in the recently adopted Core Science Curriculum Framework in Connecticut (2004). In grades 6-8, various engineering elements were included in the "Science and Technology in Society" content area but the emphasis was placed on the contribution of science toward modern technologies not necessarily toward technical literacy. Contrary to common belief, technical literacy is not the same as directly applying specific technology. ${ }^{[10]}$

The purpose of this paper is to present a thematic approach to an engineering education frameworks titled, Engineering Education Frameworks (EEF) (Appendix A) and to describe how these frameworks can foster technical literacy in the secondary school classroom. They were developed by a committee of four graduate students who were funded by a National Science Foundation grant titled, da Vinci Ambassadors in the Classroom - The Galileo Project (NSF Project \#DGE-0139307). The committee of graduate students consisted of three Ph.D. engineering students (electrical and mechanical) enrolled in the School of Engineering and one Ph.D. student enrolled in the Neag School of Education (science education). It was our intent to develop a set of guidelines that addressed technical literacy for secondary public schools.

"Proceedings of the 2005 American Society for Engineering Education Annual Conference \& Exposition Copyright $(\mathrm{C}) 2005$, American Society for Engineering Education” 
EEF was developed to propose changes to the current paradigm of compartmentalized science content that is predominant in secondary schools throughout the nation. These frameworks facilitate and promote the simultaneous teaching of multiple science disciplines in concert with mathematics while incorporating engineering concepts and designs. In order for these frameworks to serve as a successful catalyst for reform, math and science teachers must shift their pedagogy from a purely discipline specific content driven curriculum toward one that is based upon inquiry into modern technologies using authentic engineering problems as a multidisciplinary approach. A paradigm shift of this magnitude requires reshaping the way we think about teaching, learning and training future teachers of science and mathematics. A fundamental understanding of how technologies work and are applied to relevant social problems is the central focus of EEF. This approach addresses the fact that technology should be emphasized as a fundamental subject matter as opposed to merely existing as a tool ${ }^{[11]}$.

\section{Principle Aim and Direction for the Engineering Education Frameworks}

As stated in the principle aim of EEF, it is our goal

"to produce a technically literate society proficient with state-of-the-art engineering tools. To accomplish this end, it is necessary for students in grades 9-12 to develop sophisticated and systematic methods for the exploration, understanding, and improvement of technology. This is accomplished by providing a rich experience in multidisciplinary research, decision making and problem solving which unifies mathematical, scientific, socioeconomic and ethical principles to practical applications."

Since there is no single definition for technical, or technological, literacy, researchers have defined it in several different ways. Rutherford ${ }^{[11]}$ states that "technical literacy is the understanding of technology, as opposed to the ability to use it" whereas in the Waetjen article ${ }^{[12]}$, several authors' differing definitions are explicated. Technical literacy as defined in EEF refers to the ability of an individual to make informed decisions based upon an evolving understanding of the fundamentals of modern technologies.

The EEF document is divided into two major sections: Content Standards and Engineering Tools. The content standards outline the concepts needed to foster students' understanding and achievement of technical literacy by the time they complete four years of high school. Although these standards focus on and are written for secondary education (grades 9-12), we believe that technical literacy is best achieved by studying it throughout the entire K12 educational experience. The goals, as written in the Content Standards, include the following statements.

"The products of modern technology permeate our everyday lives. In order to produce a technically literate society, it is imperative that the basic concepts underlying these technologies be understood. Specifically, technical literacy

"Proceedings of the 2005 American Society for Engineering Education Annual Conference \& Exposition Copyright $($ C 2005, American Society for Engineering Education” 
can most effectively be achieved by revisiting the most relevant of modern technologies as recurrent themes consistent with the principle aims. Modern technology themes include, but are not limited to: Information and Communications, Sources of Power/Energy, Transportation, and Food \& Medicine."

Within the context of the Content Standards, EEF addresses four specific content areas are outlined: Information and Communications, Sources of Power/Energy, Transportation, and Food \& Medicine. It is assumed that these content areas are the basis of modern technology advances and applications to date. These content areas are dynamic in nature and will evolve as technology itself evolves.

In the second section, Engineering Tools, its focus is to address the necessary tools required to implement the Content Standards. As stated, the goals outlined in the Engineering Tools section consist of the following statements.

"Engineering tools are essential in the simplification, management, and communication of complex tasks ranging from academic inquiry to personal application. Due to the complexity of these content standards, many of these tools are required for their meaningful exploration. Proficiency with these tools is expected to be acquired cumulatively over the tenure of a high school career."

It is important to note in this section that we define an "engineering paradigm." This engineering paradigm outlines specific steps or a methodology in order to implement the engineering process. It explicitly describes how students can solve problems in a similar manner to engineers and encourages this decision making process when tackling problems associated with the Content Standards. The engineering paradigm objectives are stated below.

"The Engineering Paradigm is a systematic methodology that allows a technically literate person to gain perspective into the logical decomposition of a problem and its iterative procedure toward a solution. The topics covered in these content standards can only be explicitly understood in this context. More specifically, this is the fundamental tool for exploration, understanding, and improvement of the content covered in the Standards. In addition, this Engineering Paradigm provides an analytical thought process that can be extended to addressing other problems beyond the traditional scope of engineering and technology. Finally, it is imperative that a technically literate society be able to compare and contrast the products that it uses. This paradigm enables consumers to evaluate the functionality and capabilities of products in terms of design optimization and the trade-offs inherent in satisfying multiple constraints. This paradigm is outlined below.

- Problem recognition and definition

- Problem decomposition 
- Piecewise analysis

- Preemptive generation of possible solutions

- Consideration of constraints

- Iterative revision of possible solutions

- Iterative prototyping until an acceptable product

- Final design optimization"

Within the realm of the Engineering Tools section, it is essential to state that the integration of multiple disciplines including mathematics, the sciences, social sciences and computer applications that fully enables a meaningful exploration into technology, its development, and its applications all entwine in the understanding of engineering. EEF reinforces the belief that engineering is a multi-disciplined approach to problem solving and it is essential to acknowledge all the tools to make that process possible.

As mentioned earlier, the ITEA has developed technology education standards that promote technical literacy. Although the ITEA has developed comprehensive K12 guidelines; there are two fundamental differences between ITEA document and EEF. First, the ITEA has outlined technology content as an independent, isolated field of study. This strategy suggests a lack of integration with the existing science curriculum whereas EEF attempts to promote technology content in the context of and collaboration with existing mathematics and science curriculum. Second, the ITEA technology standards have listed several engineering tools within their curriculum content. EEF includes engineering tools as a distinct, but related area, and suggests that these tools facilitate the study of technological systems while preserving the four areas of technology as the core curriculum content. Although the two have their distinct differences in their fundamental approach, each in its own right has initiative to foster technical literacy.

\section{Conclusion}

The Engineering Education Frameworks (EEF), as proposed in this document, provides a means for comprehensively integrating technology and engineering content within the frameworks of existing mathematics and science curriculum. Resistance to change in a predominantly traditional high school setting is a hurdle that must be overcome in order for these frameworks to be implemented in secondary school classrooms. Resistance to change is not an easy task to overcome as $\operatorname{Evan}^{[13]}$ articulates. From that start of their educational experience, preservice teachers' training and teachers' continued professional development must be the catalyst to drive this new pedagogical paradigm. EEF provides the context to guide teachers' of science and mathematics into inquiry based lessons using relevant social issues that is currently being tackled by engineers today. It is at this level that change can commence. Since our goal is for mathematical, scientific and technical literacy for all students, it is essential to change the paradigm of teaching mathematics and science from the traditional content driven, discipline specific model to an authentic problem based inquiry model. EEF provides a core to facilitate students' understanding of authentic technological systems while reinforcing mathematics and science disciplines resulting in mathematic, science and technical 
literacy. To accomplish this goal is both the current challenge as well as the beginning of a new way of thinking about mathematics and science education.

\section{$\underline{\text { Acknowledgements }}$}

This paper was sponsored by a NSF supported grant titled, de Vinci Ambassadors in the Classroom, the Galileo Project (NSF Project \#DGE-0139307). Discussions began during a course taught in the Fall of 2003 through the University of Connecticut's Neag School of Education under the direction of Dr. David Moss. Special thanks for NSF and the Galileo Project PI, Dr. Kazem Kazerounian for funding this project.

\section{$\underline{\text { References }}$}

1 Bame, E.A., W.E. Dugger Jr., M. deVries, and J. McBee. Pupils' Attitudes Toward Technology-PATTUSA. Journal of Technology Studies 19(1). 40-48. 1993

2 DeBoer, G.E.. Scientific Literacy: Another Look at Its Historical and Contemporary Meanings and Its Relationship to Science Education. Journal of Research in Science Teaching. 37(6). p. 582-601. 2000

3 Bybee, R. W. Achieving Scientific Literacy: from Purposes to Practices. Portsmouth, NH: Heinemann. 1997

4 Shamos, M.H. The Myth of Scientific Literacy. New Jersey: Rutgers University Press. 1995

5 American Association for the Advancement of Science. Science for All Americans: Project 2061. New York: Oxford Press 1989

6 American Association for the Advancement of Science. Benchmarks for Science Literacy.. New York: Oxford Press. 1993

7 National Science Teachers Association. Scope, Sequence and Coordination of Secondary School Science. Vol. 1, The Content Core: A Guide for Curriculum Designers. Washington, DC: Author. 1992

8 National Research Council. National Science Education Standards. Washington, DC: Academy Press. 1996

9 Standards for Technological Literacy: Content for the Study of Technology. The International Technology Education Association. Reston Virginia 2000, http://www.iteawww.org/TAA/PublicationsMainPage.htm

10 Hayden, M.A. The Development and Validation of a Test of Industrial Technological Literacy, Journal of Technology Education, v3, no1 1998 http://scholar.lib.vt.edu/ejournals/JTE/v3n1/pdf/hayden.pdf )

11 Rutherford, J., Technology in the Schools, Technology in Society. vol. 26, p. 149-160, 2000

12 Waetjen, W.B., Technological Literacy Reconsidered, Journal of Technology Education Vol. 4 No. 2 , Spring 1993

13 Evans, R. The Human Side of School Change: Reform, Resistance and the Real-Life Problems of Innovation. San Francisco, CA: Jossey-Bass Publishing. 1996

\section{Biographical Information}

"Proceedings of the 2005 American Society for Engineering Education Annual Conference \& Exposition Copyright (C) 2005, American Society for Engineering Education" 
CATHERINe KoeHLeR is a Ph.D. candidate in the Neag School of Education at the University of Connecticut. Her field of study is curriculum and instruction concentrating in science education under the direction of David M.

Moss. Her dissertation work explores a pedagogical model of teaching the nature of science to secondary science teachers. She has taught Earth Science, Physics and Forensic Chemistry in public high school for 7 years prior to her graduate school training. Currently, she is a full time science education faculty member at Central Connecticut State University in the Department of Physics/Earth Science.

ELIAS FARACLAS is a doctoral student and research assistant in the University of Connecticut School of Engineering, Department of Electrical and Computer Engineering. He earned his bachelor's and master's degrees in Electrical Engineering at UConn in December 2000 and 2004, and is currently completing his doctoral studies in Electrical Engineering. Presently, Mr. Faraclas is researching InP-based HEMT's for low-noise applications and GaN-based HFET's for high power and high temperature applications. He is completing his doctoral studies as a National Science Foundation Galileo Fellow. Mr. Faraclas is also a Research and Design Engineer at Instrument Manufacturing Company in Storrs CT.

SONIA SANCHEZ is a doctoral student and research assistant in the University of Connecticut School of Engineering, Department of Electrical and Computer Engineering. She earned her bachelor's degree in Electrical Engineering at UConn in December 2000 and is currently completing her doctoral studies in Electrical Engineering. Presently, Ms. Sanchez is researching 3D image processing and has done extensive research in the areas of lasers and optoelectronics. She is completing her doctoral studies as a National Science Foundation Galileo Fellow.

S. KHALID LATIF is a M.S. student in the School of Engineering at the University of Connecticut. His field of study is in mechanical engineering under the direction of Kazem Kazerounian. His research focus is on protein folding and modeling. He has spent over a year in high school as an engineering ambassador through the Galileo Project.

KAZEM KAZEROUNIAN is a Professor of Mechanical Engineering at the University of Connecticut. His research interests include mechanical design, robotics, chaos theory, and engineering education. He is the Chair of the ASME Robotics and Mechanisms Committee, the general conference Chair for the ASME Design Engineering Technical conferences and Computers in Engineering Conference 2002. He has served as the Associate Editor of the ASME Journal of Mechanical Design, and the International Journal of Mechanisms and Machine Theory. He is the Principle Investigator for the de Vinci Ambassadors in the Classroom, the Galileo Project. 


\section{Appendix A}

\section{Proposed Engineering Education Frameworks}

\section{Principle Aim}

The principle aim of engineering education in grades $9-12$ is to produce a technically literate society proficient with state-of-the-art engineering tools. To accomplish this end, it is necessary for students to develop sophisticated and systematic methods for the exploration, understanding, and improvement of technology. This is accomplished by providing a rich experience in multidisciplinary research, decision making and problem solving which unifies mathematical, scientific, socioeconomic and ethical principles to practical applications.

\section{Content Standards}

The products of modern technology permeate our everyday lives. In order to produce a technically literate society, it is imperative that the basic concepts underlying these technologies be understood. Specifically, technical literacy can most effectively be achieved by revisiting the most relevant of modern technologies as recurrent themes consistent with the principle aims. Modern technology themes include, bur are not limited to, Information and Communications, Sources of Power/Energy, Transportation, and Food \& Medicine.

\section{A. Information and Communication}

This modern age has often been heralded as the age of information. Never before in the history of the world has so much information been collected, organized, and made readily available to so many people. Communication allows us the opportunity to disseminate and access this information. Central to the understanding of technical systems of this nature are the various means of storing, transmitting, receiving, and protecting this information. Students should be able to compare and contrast the trade-offs and figures of merit for such systems.

\section{Instruments}

Information is only useful if it is accessible for viewing and manipulation. With vast improvements in computing power and memory availability, the capabilities of even common electronic devices are often taken for granted. Furthermore, many of the features of these devices are often not understood or even unknown by the majority of users. As the demand for information continues to increase, it is essential that students have a working knowledge of the capabilities of the instruments of communication on a more fundamental and technical level. As a result of instruction and direct experience with modern instruments, such as computers, cell phones, digital audio and video devices etc., students should:

- Understand how the data is stored and manipulated on each instrument.

- Understand the basics of communication between instruments.

- Exhibit familiarity with common user interaction with such instruments.

- Recognize the basic similarities (i.e. all devices are more or less similar in operational concept and they can easily be operated with general familiarity).

- Identify missing pieces and be able to conceptualize possible solutions.

- Understand the limitations of current instruments in terms of current technology and infrastructure.

- Make realistic predictions about the future of such devices.

- Understand the different architectures and hardware components of a computer.

- Processors

○ Memory

"Proceedings of the 2005 American Society for Engineering Education Annual Conference \& Exposition Copyright $(\mathbb{C}$ 2005, American Society for Engineering Education” 
- Non-volatile data drives

- Peripherals and interfaces

- Compare and contrast the integration of these into various computer systems.

\section{Mediums}

Communication is the exchange of information. There are many ways to transmit this information over a variety of media using a host of coding methods. Modern mediums of communication include, but are not limited to, wired-lines, fiber-optic cables, and air / free space. Information is generally either an analog or digital signal which is coded using a host of modulation schemes. Students should be able to compare and contrast the media and coding schemes of various systems in terms of their quality, accessibility, economy, and reliability. Current systems that should be studied include:

- Computer networks (data sharing).

- Voice and other personal communication systems.

- Broadcast information and entertainment.

\section{B. Sources of Power/Energy}

Energy from various sources is fundamental for powering our homes, businesses, means of transportation, and many other everyday objects. Our lives are dependent on the energy that we consume and the future of our society is inextricably linked to the development of new energy sources and power supplies. A technically literate person will be able to understand the technical capabilities, efficiencies, environmental ramifications, safety and security issues of the various sources of energy that are currently used as well as those being considered for future use.

Students should have hands-on experience with alternate energy sources and systems, such as batteries, wind, geothermal, fossil fuels, hydropower, solar, etc. They should also be exposed to the capabilities of other sources, such as nuclear power, as well as the current state of research and development of other promising power and energy technologies. As a result, students should be able to compare and contrast the various energy sources as well as:

- Evaluate the available sources as well as promising future sources.

- Discuss the advantages and disadvantages associated with a given energy source.

- Analyze the efficiencies of the various sources.

- Predict the longevity of the energy supplies.

- Evaluate their various environmental impacts.

- Discuss their political and economic ramifications.

\section{Transportation}

One of the prominent applications of modern technologies is the development and maintenance of transportation systems. Personal commuting, recreational vehicles and mass transit systems are universally used on a daily basis. Our global economy is inextricably bound to our ability to move products quickly and efficiently. Currently, our range of vehicles is dependent on fossil fuels, specifically oil. Since this is a limited resource, it is vital to understand alternate energy sources in the context of the vehicles that they will power. As vehicles and their byproducts are significant contributors to pollution and other environmental detriments, it is important to focus on them specifically for future improvements. It is also important to consider the vehicular integration of electronics and information systems for convenience, entertainment, and safety. In order to study technology in transportation, students should focus on:

- Engines. 
- Internal Combustion, Jet/Turbine, Rockets, electromagnetic

- The fundamentals of their operation

- The types of applications can each engine be found in

- Tradeoffs

- Dependency on fuel types.

- Economy.

- Environment.

- Safety.

- The technology involved in current safety features

- The future of safety features

\section{Food \& Medicine}

It has become extremely important to understand how to provide for the health of our increasing and aging population. New medicines and technology are constantly demanded to increase life expectancy and decrease mortality and morbidity rates. The associated costs of development, means of distribution, and ethical ramifications of these need to be considered. Genetic engineering has also become a focus for protecting and increasing the food supply for the growing populace. In order to address these and evolving issues, it is important for students to understand how to make informed decisions that affect the future health status of the population as well as its sustainability. A technically literate person will be able to evaluate the impact on a population based on knowledge of how the various engineering disciplines affect food and medical technology. Fundamental concepts and principles that underlie this standard include engineering in food and medicine.

\section{Engineering in Food}

To increase productivity and quality of food for a growing industrialized country, it is necessary to develop food products that can flourish in the face of non-ideal conditions. The modern trend has been to genetically alter foods to increase net yield. Other engineering applications include the artificial enhancement of plants, animals, and the environment for maximum yield. Students should be able to:

- Identify foods that have been genetically altered or artificially enhanced.

- Explore the needs and benefits for genetically altered food.

- Understand the process for genetically altering a food.

- Debate the need of a plentiful food supply using artificial enhancements, such as pesticides, versus the negative anticipated impacts.

- Understand the artificial environments needed to sustain a renewable food supply.

\section{Engineering in Medicine}

Engineering new technologies in the medical field is driven by our innate drive for sustaining the quality of life. Although engineers are responsible for producing technologies, the sustainability of groundbreaking research is often strongly dependent on the ethical consensus of the political population. Students should be able to:

- Identify the role of technological advances in

- Diagnostic and measurement instrumentation.

- Prosthetics and replacement body parts.

- Artificial bio-enhancements.

- Pharmaceuticals as they maintain homeostasis.

- Evaluate the impact of current engineering technologies in medicine.

- Debate the political, ethical, and socioeconomic issues surrounding future 
development.

\section{Engineering Tools}

Engineering tools are essential in the simplification, management, and communication of complex tasks ranging from academic inquiry to personal application. Due to the complexity of these content standards, many of these tools are required for their meaningful exploration. Proficiency with these tools is expected to be acquired cumulatively over the tenure of a high school career.

\section{A. Engineering Paradigm}

The Engineering Paradigm is a systematic methodology that allows a technically literate person to gain perspective into the logical decomposition of a problem and its iterative procedure toward a solution. The topics covered in these content standards can only be explicitly understood in this context. More specifically, this is the fundamental tool for exploration, understanding, and improvement of the content covered in the Standards. In addition, this Engineering Paradigm provides an analytical thought process that can be extended to addressing other problems beyond the traditional scope of engineering and technology. Finally, it is imperative that a technically literate society be able to compare and contrast the products that it uses. This paradigm enables consumers to evaluate the functionality and capabilities of products in terms of design optimization and the trade-offs inherent in satisfying multiple constraints. This paradigm is outlined below.

- Problem recognition and definition

- Problem decomposition

- Piecewise analysis

- Preemptive generation of possible solutions

- Consideration of constraints

- Iterative revision of possible solutions

- Iterative prototyping until an acceptable product

- Final design optimization 


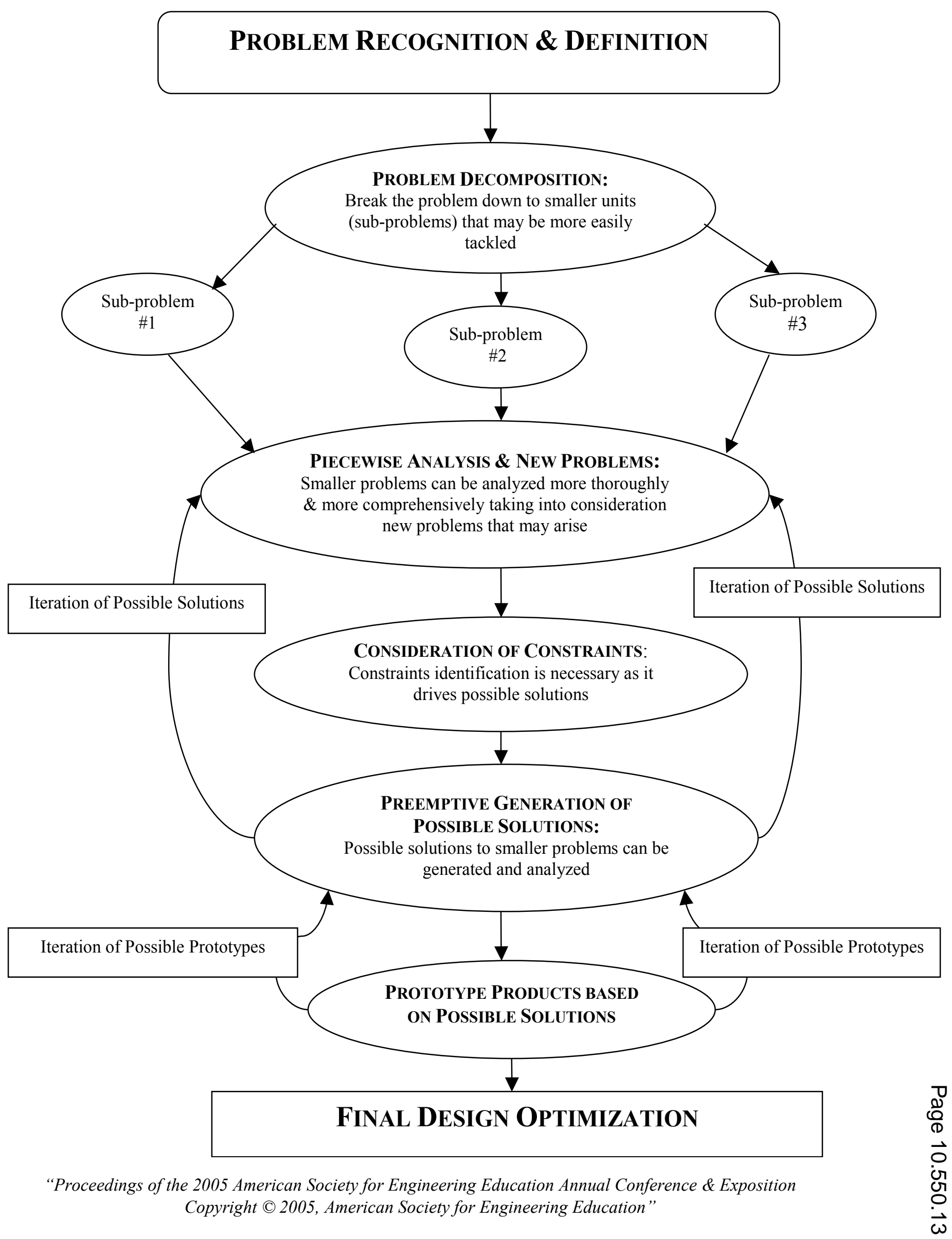




\section{B. Science and Mathematics}

All technology is ultimately derived from the application of scientific and mathematical principles. Therefore, a solid foundation in these disciplines is essential for facilitating a comprehensive understanding of the content standards. The following should be covered in the course of a high school education.

\begin{tabular}{|l|l|} 
Science Disciplines & Math Topics \\
\hline Biology & Geometry \\
Chemistry & Algebra \\
Physics & Trigonometry \\
& Calculus \\
\hline
\end{tabular}

Table 1: Recommended Science Disciplines and Math Topics

\section{Social Sciences}

Engineering, as a discipline, is focused on improving society by satisfying its everchanging technological needs. Thus, while technology is derived from scientific and mathematical principles, its development is predominantly driven by sociological motivation and constraints. It is important that these factors be considered in the study of any technical system. Furthermore, the Engineering Paradigm outlines an iterative approach toward final design optimization. This process is by no means limited to technical constraints but must also satisfy its sociological requirements. It is important that the Content Standards, and their sociological optimization, are studied in the context of:

- Sociology

- Economics

- Ethics

- Politics

\section{Computer Tools}

Our society is inextricably bound to the computer infrastructure that supports it. Technical literacy thus increasingly requires proficiency with various computer tools and applications to effectively interact within our technologically advanced environment. However, the engineering community is absolutely dependant on its computer tools for system development. Because of the complexity of these systems, such as those covered in the Content Standards, the use of computer tools greatly enhances their meaningful and thorough exploration. Students should have a working knowledge of the following computer tools.

- General computing

$\circ$ Word processing

- Spreadsheet

- Communication tools

- Presentation tools

- Familiarity with operating systems

- Computer Programming

- Algorithmic synthesis and decomposition

- Implementation of computer-based models

- Computer aided drafting / drawing 